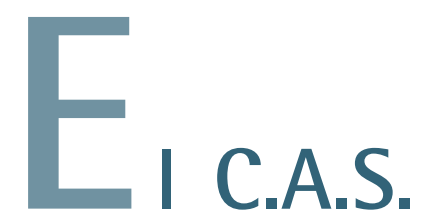

\title{
un hallazgo para el Balneario de La Palma
}

\section{Antonio Martín Molina Montserrat Díaz Recaséns}

Arquitectos

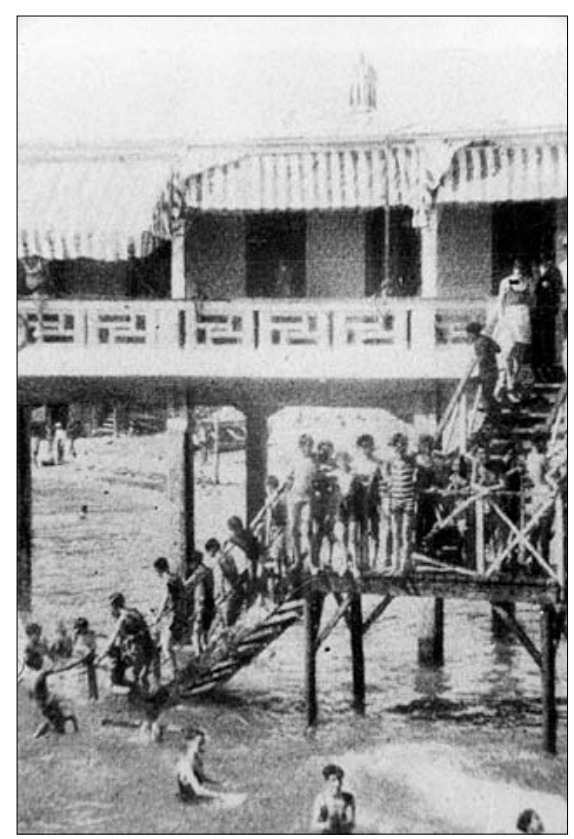

\section{Los comienzos}

Escribir sobre el Balneario de la Palma significa, para nosotros, no sólo revisar ya viejos archivos, sino también revivir incertidumbres y emociones pasadas.

En el año 1989 recibimos el encargo de la restauración del Balneario de la Palma por la Dirección General de Bienes Culturales. Se trataba sin duda de un encargo singular en muchos sentidos, pues no solo era infrecuente la intervención de la Consejería de Cultura en edificios tan recientes sino que no se fijó inicialmente ni el presupuesto ni el uso futuro. Solo se nos trasladó y eso no era poco, la voluntad clara de evitar la demolición del edificio.

Nuestro primer informe apareció en 1990, casi simultáneo con el elaborado por la empresa Vorsevi. Ellos habían demostrado la viabilidad de la restauración con un proyecto basado en los ensayos y estudios realizados en las ruinosas estructuras existentes. Nosotros, documentábamos la historia, los antecedentes tipológicos y exploramos diversas posibilidades de uso.

Recabamos la opinión de algunos técnicos y otras personas vinculadas con Cádiz, pensando que encontraríamos sugerencias y una larga lista de necesidades y reivindicaciones, pero la verdad es que, salvo las siempre honrosas excepciones, encontramos más escepticismo que ayuda para el proyecto. Creíamos que Cádiz debía recuperar argumentos reales de desarrollo, nuevas iniciativas y proyectos singulares no necesariamente ligados a la hostelería. Pensábamos en proyectos públicos o privados que además de recuperar el edificio, tuvieran la solvencia precisa para asegurar la continuidad del uso y justificar las cuantiosas inversiones previsibles.

A modo de ejemplo, estudiamos la posibilidad de construir una piscina cubierta. Esta propuesta novedosa entonces en Cádiz, era en cierta forma una restauración también del uso del Balneario y su rentabilidad estaba asegurada como se comprobó por estudios económicos que se realizaron. Desconocemos si el rechazo municipal al proyecto se debió a causas políticas o a argumentos consistentes, nunca lo supimos. El destino del edificio volvió a quedar en suspenso una buena temporada, y la Consejería optó por la ejecución de obras de emergencia, apuntalamiento y consolidaciones puntuales a la espera de una definición del proyecto.

La búsqueda de galeones españoles en el Caribe o el expolio casi sistemático de la Bahía de Cádiz son seguramente el germen del Centro de Arqueología Subacuática (CAS). La arqueología, que en estos años progresaba constante en Andalucía nos ofrecía un argumento tan atractivo como incuestionable.

El Instituto Andaluz de Patrimonio Histórico (IAPH), junto a Costantino Meucci químico del Instituto del Restauro Italiano, pusieron a punto el programa. Era, como no podía ser de otra forma, ambicioso y lleno de novedades. Con ellos nos entendimos a la perfección. Bastaron unas pocas reuniones para comprobar que el edificio "funcionaba". Quizás era un poco justo de tamaño, no tenía posibilidad de crecer, ni tenía 
Cuando las obras finalizan, ya nada retiene a los arquitectos y se debe dejar el paso. Las ideas, ya construidas, dejan de pertenecernos y son ya de todos. A los usuarios les toca ahora afinar el edificio, completarlo, mantenerlo y cuidarlo de las agresiones de los temporales, de la desidia y de la falta de sensibilidad y como en cualquier otro barco, con constancia, paciencia y esmero.

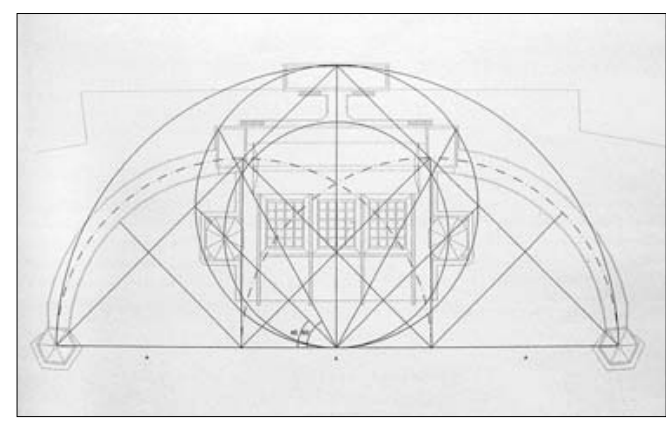

embarcadero, ni una gran zona expositiva, pero también tenía muchas ventajas y empezar era importante pues se hacía ya tarde para el viejo Balneario.

La redacción del proyecto fue complicada a pesar del exhaustivo conocimiento que teníamos del edificio. Había que moverse con máxima cautela entre extremos siempre peligrosos. Así, debíamos encontrar el punto justo donde el edificio es taller o zona de investigación o área didáctica y también, el equilibrio entre la obra nueva, la restauración y la reconstrucción. Estas fueron cuestiones siempre delicadas. Asimismo, fue complejo recuperar y hasta manipular sutilmente el sistema de proporciones y los trazados reguladores que habíamos detectado y por último, debíamos ser cuidadosos con la elección de los materiales en el difícil compromiso entre la durabilidad y el aspecto. Esta declaración de intenciones se fue ajustando a la realidad en la ejecución de las obras.

\section{Algunas notas sobre el edifico y el proyecto}

El edificio del Balneario interesaba, más que por su historia o su construcción, por la singularidad de su arquitectura y su emplazamiento, que lo había marcado como un símbolo en la memoria de la ciudad.

Al ser un edificio volcado al mar, ha presentado a la ciudad, al Paseo de las Delicias, su parte menos atractiva, casi una trasera, y ha contribuido por esta causa a que se pensara que no era una construcción de interés, y de la que se podría prescindir.
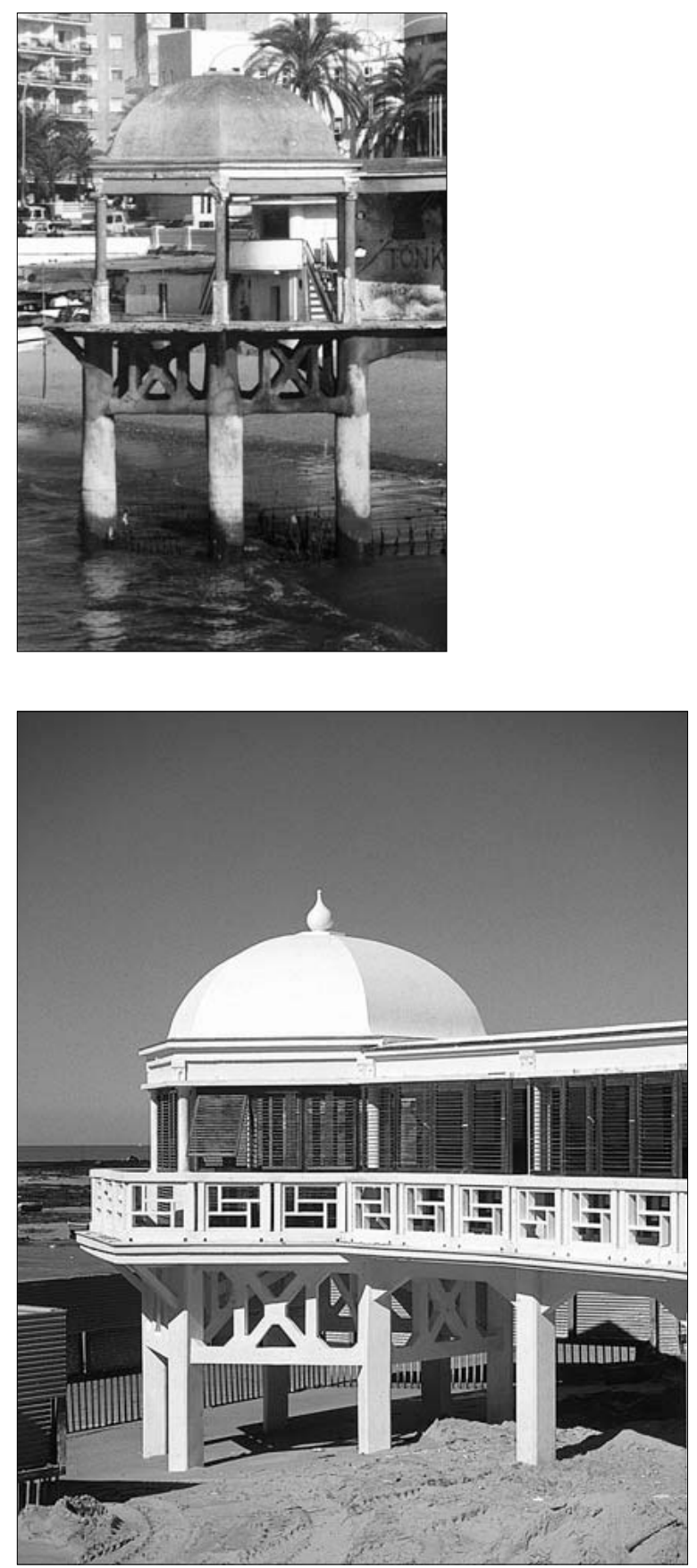

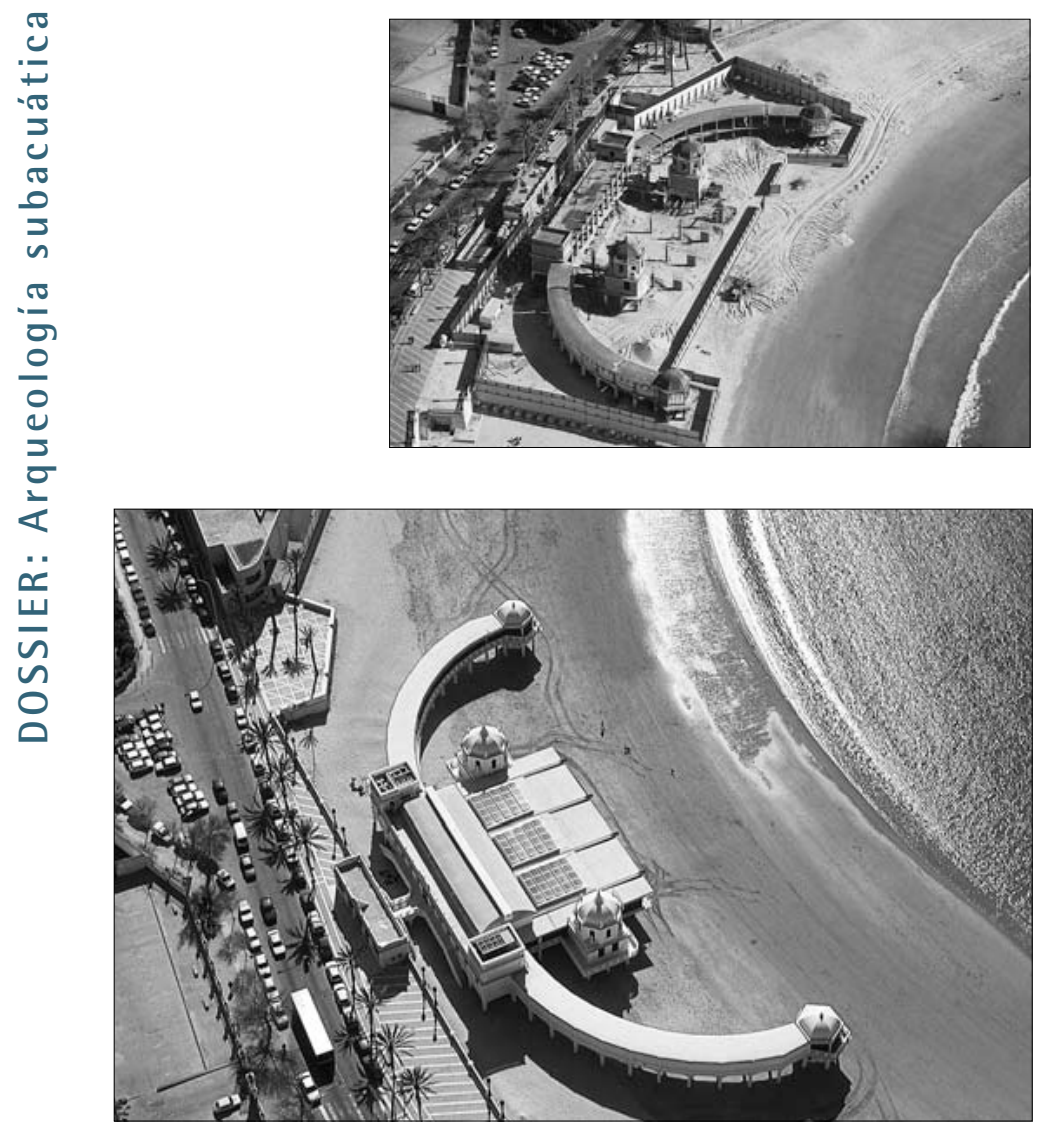

El planteamiento del Balneario como edificio autónomo es una cuestión que desde el comienzo del trabajo, nos ha parecido relevante. Se conecta con el paseo a través de una fina pasarela de forma que con marea alta, tenemos la sensación acusada de plataforma sobre el mar. No tiene en ningún momento voluntad de construir ciudad. Incluso en los planos originales no se dibuja el pequeño pabellón de entrada. Arquitectura sin referencias urbanas que sin embargo ha conseguido con el tiempo una integración en el paisaje urbano y hacerse perdurable con abundantes referencias en la iconografía de Cádiz.

Se trataba de destacar o de poner a punto la singularidad e interés de este edificio, reconstruyendo las trazas perdidas para albergar unos usos que, de alguna forma, fueran también un símbolo y un reclamo para Cádiz.

Uno de los primeros pasos fue descubrir la claridad de su trazado geométrico, que sin embargo la realidad constructiva demostraba que no estaba bien entendido o ejecutado, con múltiples errores en las intersecciones de esta geometría teórica. Esto se debió seguramente a las circunstancias en que se construyó el edificio. El proyecto original fue resultado de un concurso restringido, en el que el proyecto ganador del arquitecto García Cañas, es dirigido en su obra, con modificaciones, por el arquitecto provincial Romero Aranda y a cargo del "eficaz ingeniero constructor" A. Levenfeld. Por otro lado, el corto plazo de ejecución, hace pensar que si bien existe una sólida base de tra- zado, en la solución de los detalles se atendieron más las apariencias que el buen hacer. Quedaría por demostrar si se era consciente de los graves problemas derivados de esta situación, tanto en el proyecto como en la ejecución del edificio.

El cuerpo central tiene con las galerías laterales relaciones geométricas y visuales, pero no compositivas y estructurales, formando un atípico y débil ensamblaje entre estas partes.

En el nuevo proyecto la complejidad de estos encuentros había que resolverla con claridad y solidez. Las dos escaleras, a modo de "bisagras" tenían que absorber el encuentro de dos formas geométricas y desde el punto de vista constructivo, las juntas de dilatación.

Optamos por abrir un paso bajo ellas que diera consistencia a estos puntos de articulación del trazado, y nos pareció lo más adecuado hacerlo a la manera tradicional con bóvedas de rasillas, que nos permitía poner en valor el espacio bajo la escalera y quitarle el carácter de paso secundario que pudiera tener.

Unos segundos pasos iban encaminados a comprender que tipo de edificio se necesitaba para ese uso de Centro de Arqueología Subacuática. Tenía que ser un edificio casi industrial, una gran nave de laboratorio para estabilizar y restaurar piezas extraídas o rescatadas del mar, después de centenares, o incluso miles de años. Era por tanto también un edificio para la investigación con lugares suficientemente apartados para la reflexión y el estudio. Finalmente, y no menos importante, era la necesidad de que fuera un edificio que como un museo ayudara a la difusión de esta relativa nueva forma de entender la arqueología y que podría dar lugar a que se generaran nuevas profesiones. Por tanto, la exposición al público, a la sociedad, no era sólo de las piezas extraídas al mar, sino también había que enseñar la forma de "cómo se hacía", había que enseñar este nuevo enfoque de la arqueología que para Cádiz, por ser ciudad milenaria y relacionada siempre con el mar, sería del máximo interés.

Dejamos, por tanto, que el propio edificio nos fuera contando como debería de usarse cada una de sus partes.

Un gran espacio central, amplio, con un entramado de iluminación cenital que repartiera la luz uniformemente, sin centralizar la atención; abrigado por los laboratorios especializados que pueden alcanzar un alto grado de humedad cercano a la saturación, de maderas, metales y cerámicas, y por las vitrinas, acristalado todo por ambas caras para poder observar el trabajo que allí se realiza y captar el máximo de luz natural indirecta. Un pasillo perimetral exterior que discurre entre la carpintería acristalada y la celosía de madera separada del cristal a modo de doble piel, marcado por un zócalo de azulejos vidriados de color, permite observar como se restaura la madera, el metal o la cerámica y en general como se hace el trabajo en la nave central sin interferir ni distraer. 
Las complejas instalaciones, además de la climatización que discurre por el perímetro, de aire comprimido, aspiración o vacío, agua desmineralizada, agua y toma de corriente, necesarias para las restauraciones de las piezas, se llevan siempre vistas y registrables hasta el centro de la gran sala que, por un sencillo mecanismo de manivela, baja sobre unas bañeras móviles, donde se sumergen las piezas. Se consigue así el máximo grado de flexibilidad en el trabajo. Las torres de climatización se colocan en las dos únicas torres con azotea plana que existen, sobre los núcleos de aseos y el grupo electrógeno y la sala de máquinas se sitúan en el único cuerpo del edificio que conecta con tierra firme.

El estudio e investigación de archivo, así como un laboratorio de restauración, una vez que las piezas sacadas del mar se han tratado, se desarrolla en las dos alas, organizadas con un mueble de estantería corrido longitudinalmente por donde también se puede registrar la instalación de estas zonas. Finalmente el plan de difusión, además de por el pasillo perimetral de observación del trabajo, se completa con una pequeña sala de audiovisuales, junto a los despachos de dirección en la planta alta en la cabeza del edificio.

Con respecto a la situación singular de este edificio en la playa de la Caleta, parte en el mar y parte en tierra, vimos que partiendo de la premisa de liberar la playa, podíamos plantear en la zona de obra nueva, el dar cobijo a los bañistas de una forma más limpia y amplia, reduciendo el número de soportes, ocultando y protegiendo los desagües con una doble losa que quedarían conectados a tierra por el único "istmo" que es la pasarela. Esta nueva modulación se mantiene en la planta principal y nos permite que las piezas puedan venir tanto por tierra, si son de un tamaño de fácil transporte en vehículo, o por el mar si el tamaño era mayor, porque se ha previsto un gran hueco de hasta ocho metros y argollas para enganchar garruchas en el vuelo de las grandes vigas. Vuelos que a su vez nos sirven para desaguar todo el agua de los lucernarios de cubierta, mediante grandes gárgolas de zinc, al mar.

\section{La puesta en obra}

El Balneario estaba construido en hormigón de poca resistencia, secciones muy ajustadas y escaso recubrimiento de armaduras. El no conocer el comportamiento del material en su envejecimiento y la poca atención que sin duda se presto a la ejecución fueron determinantes en la ruina del edificio. El comienzo efectivo de las obras pasaba por determinar realmente aquellas partes que admitían restauración y aquellas otras que debían ser demolidas. Se amplió en consecuencia la toma de datos iniciada por los Laboratorios Vorsevi y se clasificaron las obras: restauración, reconstrucción y obra nueva.

Las obras de restauración se centraron en los elementos más significativos que aún quedaban en pie es decir, los torreones centrales, los pabellones he- xagonales extremos de las alas, y toda la crujía de fachada, así como el pabellón de entrada.

La reconstrucción se centró en las alas, pues nada quedaba en ellas de interés. Todos los elementos arquitectónicos habían desaparecido o habían sido sustituidos y la estructura estaba desfigurada por los refuerzos ejecutados en los años 70 .

Finalmente la obra nueva se ejecutó en la zona central delimitada por las restauraciones encajando pórticos de grandes luces con la estructura de las crujías de cabecera.
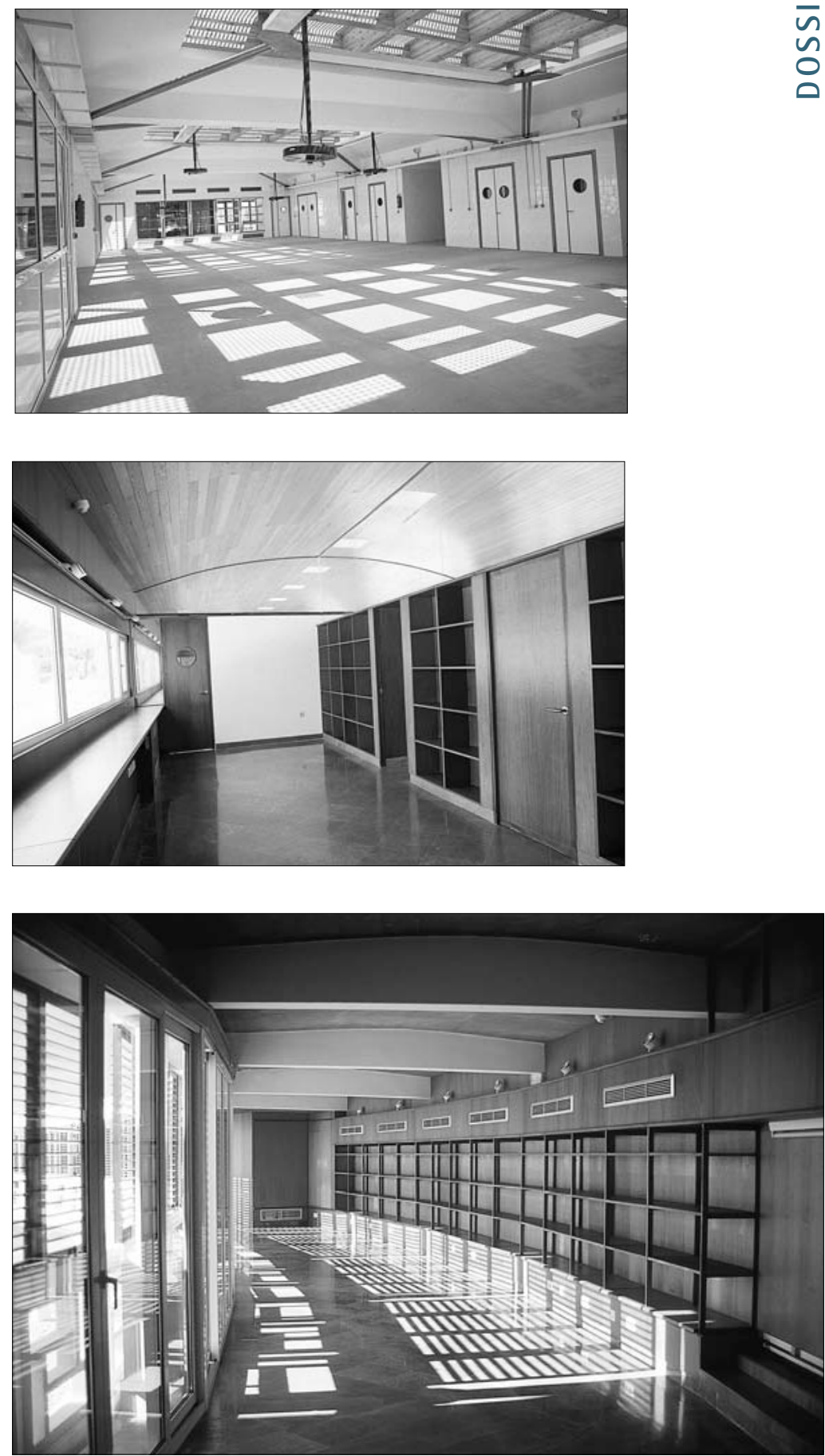


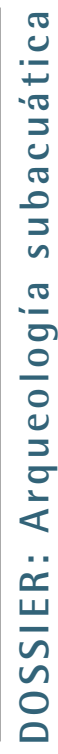
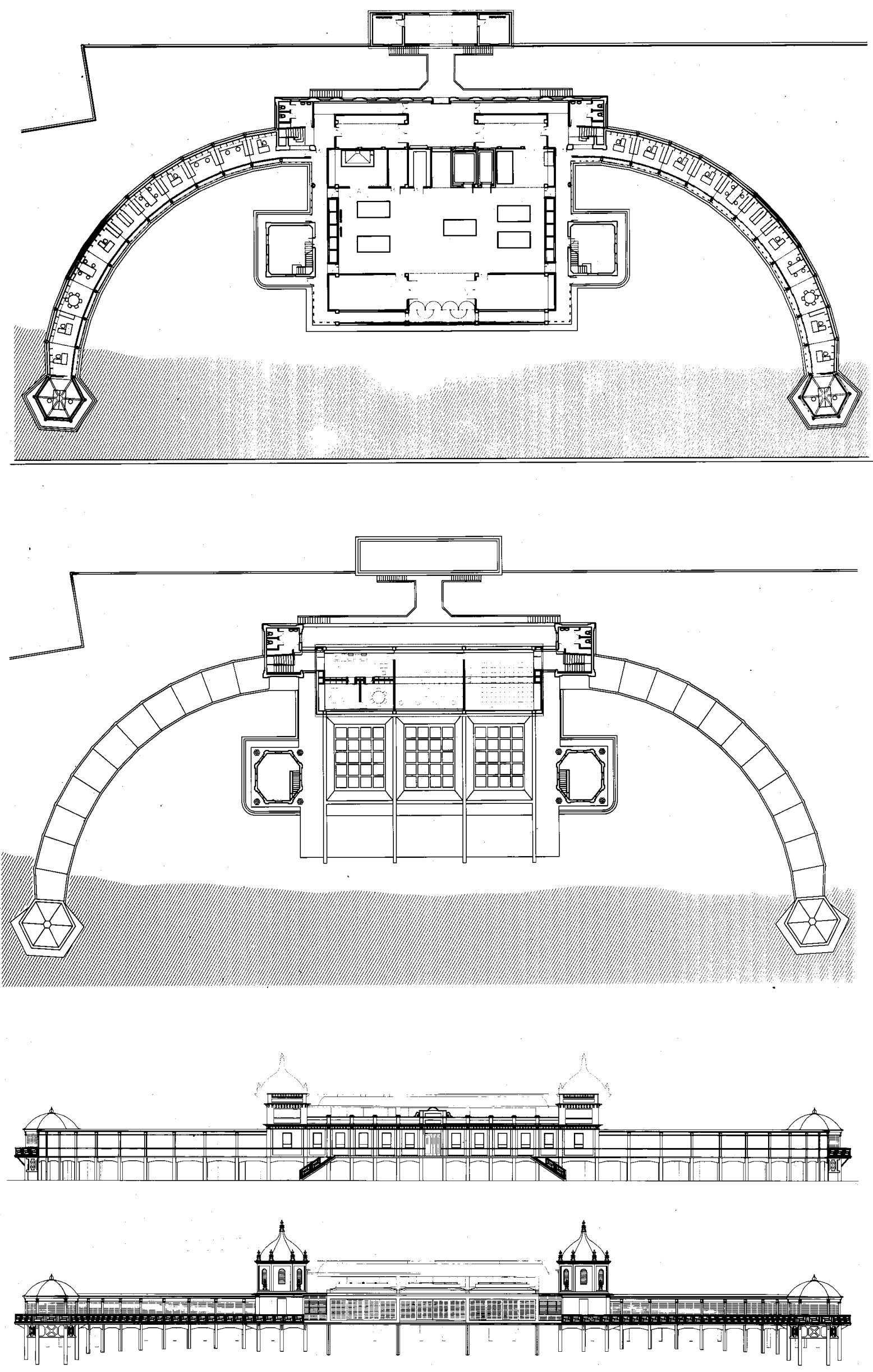
La reparación de los hormigones se ejecutó apeando el edificio y picando tanto el revestimiento gunitado como las secciones originales hasta encontrar el núcleo de hormigón sano. Posteriormente se empezó a pasivar y sustituir armaduras pasándose seguidamente a reconstruir las secciones con recubrimientos de $4 \mathrm{~cm}$. En los pilares se pudo encofrar y las losas y vigas de pequeño espesor se restauraron con morteros sin retracción. Toda la estructura tanto nueva como restaurada quedó protegida con la aplicación posterior de un mortero polimérico.

Los hormigones son $\mathrm{H}-200$ con cemento tipo SRMR resistentes a sulfatos $y$ al agua de mar. $Y$ su uso se extendió tanto a la cimentación como al resto del edificio.

La zona central se ejecutó con una doble losa nervada para alojar en su interior el saneamiento y evitar que quedara visto desde la playa.

Los elementos ornamentales, balaustradas, columnas y remates, se reconstruyeron a partir de fotografías de la época de la construcción del edificio prefabricándolas en taller, conectadas a la estructura con placas de anclaje.

El encofrado de las losas con paneles fenólicos permitió poder dejarlas vistas en las bóvedas de las alas sin más recubrimiento que una protección. En otros casos las losas eran ejecutadas como refuerzo sobre las existentes. En la obra de la planta segunda destinada a dirección, decidimos ejecutar una bóveda con la idea de que esta ampliación no ofreciera un aspecto muy distinto de otras formas existentes en el edificio. En este caso, se ejecutó un encofrado de madera de pino en listones machihembrados como un cascarón de barco. Después del hormigonado, se retiraron las "cuadernas" y no así la tablazón que quedó vista.

Otro tema determinante nos parecía la imagen exterior que se debía ofrecer, la pluralidad de recintos que se precisaban nos obligaba a intentar unificar con un solo criterio constructivo todo el edificio. La solución se encontró al proyectar los recorridos de visitantes. El circuito externo nos permitió desdoblar la fachada, una interior con carpinterías amplias de PVC y otra exterior que se ejecutó con celosías de lamas de madera de caoba del Brasil barnizada. De esta forma, el auténtico cerramiento del edificio se adivina en la trasparencia de las lamas de madera. Esta solución conlleva un mantenimiento, de la madera que sin embargo queda compensado, a nuestro juicio, frente a soluciones alternativas en otros materiales, aparentemente más fáciles de mantener pero quizás menos experimentadas en estas condiciones extremas y en todo caso menos atractivas.

También se utilizó la madera en la ejecución de los lucernarios de la sala de lavado. En este caso, se proyectó una entramado bidireccional sobre los pórticos de hormigón que repartieran abundante luz no directa, sino homogénea y reflejada.
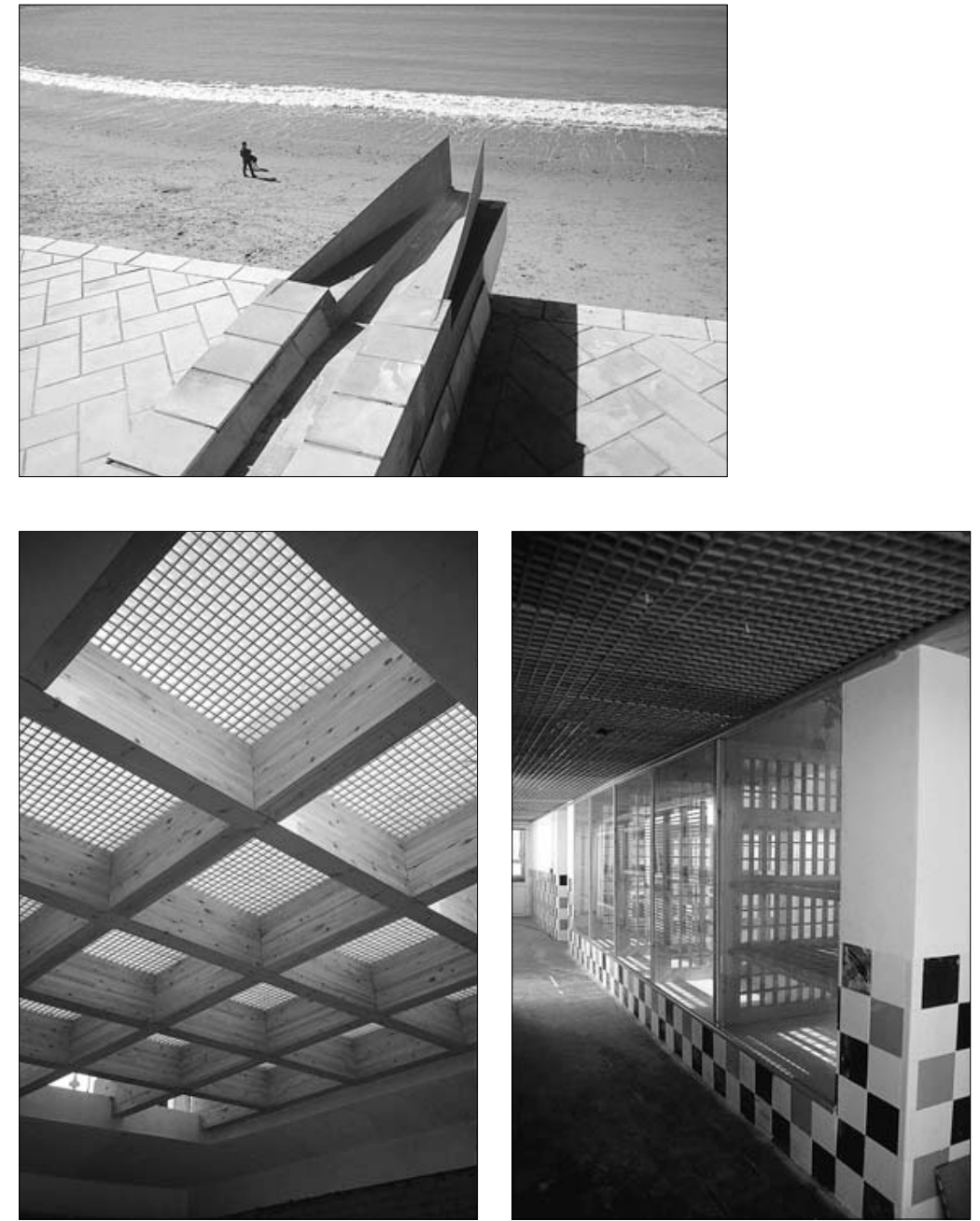

\section{Agradecimientos y recomendaciones}

Hacer realidad los proyectos nunca es una labor fácil y sería ingrato no reconocer la ayuda institucional que recibimos desde la Dirección General de Bienes Culturales, el IAPH y la Delegación Provincial de la Consejería de Cultura de Cádiz. Agradecimiento genérico que queremos concretar en las personas del Consejero Suárez Japón y en nuestros amigos Román Fernández-Baca y José María Esteban que desde sus cargos hicieron más fácil nuestro trabajo. El C.A.S. supone una iniciativa pionera, que junto a otros edificios e instituciones, es un potencial por explotar. Nos sentimos orgullosos de haber participado en este proyecto y en colaborar modestamente al desarrollo de Cádiz.

\section{...Final}

Cuando las obras finalizan, ya nada retiene a los arquitectos y se debe dejar el paso. Las ideas, ya construidas, dejan de pertenecernos y son ya de todos. A los usuarios les toca ahora afinar el edificio, completarlo, mantenerlo y cuidarlo de las agresiones de los temporales, de la desidia y de la falta de sensibilidad y como en cualquier otro barco, con constancia, paciencia y esmero.
El equipo técnico lo han formado:

Arquitectos:

Antonio Martín Molino

Montserrat Díaz Recaséns

José María Prieto Gracia

Arquitectos Técnicos

Antonio Cueto Martínez de Baños José Fernández Guareño

Empresa constructora Fomento de Construcciones y Contratas 